\title{
1. Antecedentes: perspectiva histórica
}

\section{2: a introdução da cana-de-açúcar no Brasil}

A história do Brasil está intimamente ligada à biomassa, tendo o nome "Brasil" se originado da madeira do pau-brasil ${ }^{1}$, cuja exploração constituiu a primeira atividade econômica após a chegada dos portugueses. Com o duplo objetivo de produzir açúcar, altamente valorizado na Europa, bem como "ocupar e desenvolver" as novas terras portuguesas, em 1532 a cana-de-açúcar ${ }^{2}$ foi introduzida em terras brasileiras, inicialmente na parte meridional da demarcação estabelecida pelo Tratado de Tordesilhas (Figura 1), na capitania de São Vicente, por seu primeiro donatário Martim Afonso de Souza (Figura 2), utilizando mudas trazidas da Ilha da Madeira ou de Cabo Verde 3 . Poucos anos depois, a produção de açúcar de cana foi introduzida com sucesso na capitania de Pernambuco, por Duarte Coelho Pereira ${ }^{4}$.

1 No ciclo econômico do pau-brasil, que antecedeu o da cana-de-açúcar no Brasil, a madeira era simplesmente explorada visando à obtenção de um corante natural alternativo ao azul de índigo indiano.

2 A cana-de-açúcar é uma planta pertencente ao gênero Saccharum L. Existem várias espécies do gênero, e a cana-de-açúcar cultivada é um híbrido multiespecífico que recebe a designação Saccharum spp. As espécies de cana-de-açúcar são provenientes do Sudeste Asiático.

3 Segundo Câmara (2004), as primeiras mudas de cana-de-açúcar chegaram antes, em 1502, vindas da Ilha da Madeira, trazidas por Gonçalo Coelho. Segundo o autor, Martim Afonso de Souza e outros quatro sócios construíram os primeiros engenhos, sendo que o Engenho dos Erasmos (também conhecido como Engenho do Governador) é o único que deixou vestígios: as ruínas encontram sob a proteção da Universidade de São Paulo.

4 Embora não se saiba com certeza por onde a cana-de-açúcar entrou no continente americano e como se espalhou, especula-se que, em 1493, Cristóvão Colombo teria introduzido no "Novo Mundo" a variedade Crioula, resultado de uma hibridação natural entre Saccharum officinarum e Saccharum barberi (Bremer, 1932). 


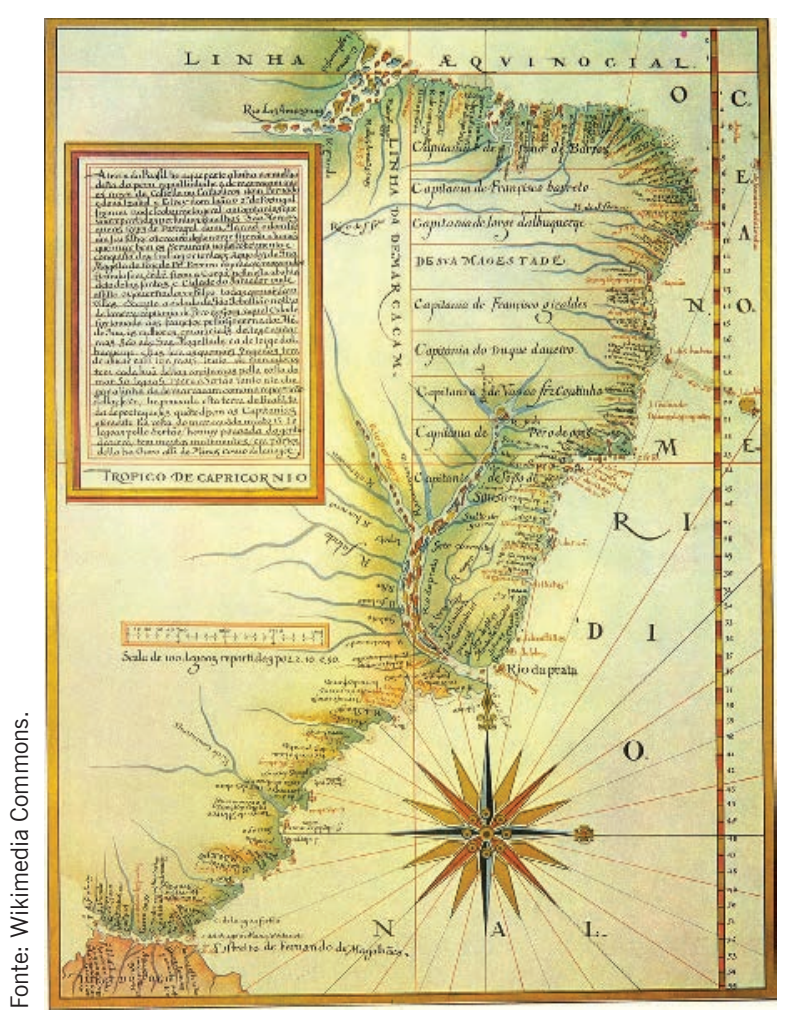

Figura 1: Capitania de São Vicente ${ }^{5}$.

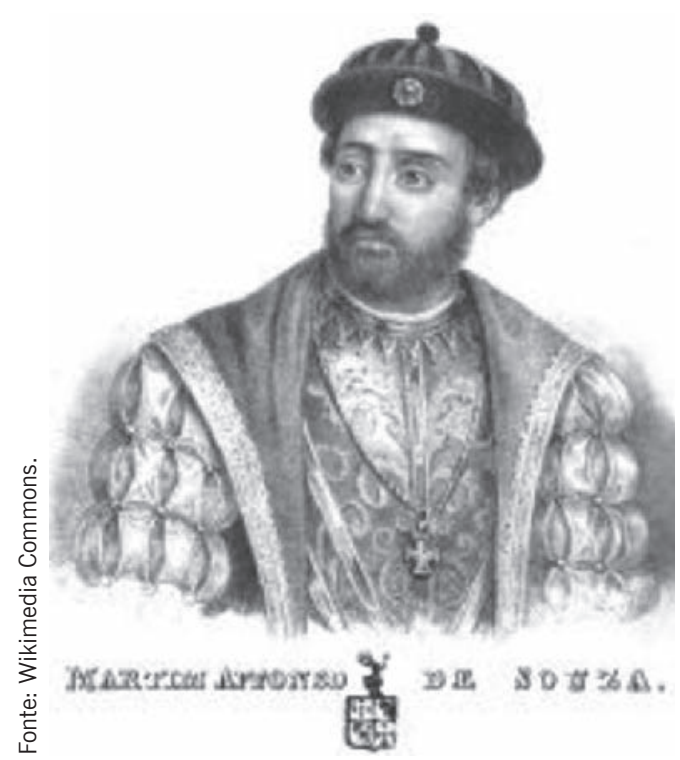

Figura 2: Martim Afonso de Souza.

\section{Séculos XVI a XIX: crescimento, instabilidade, matriz energética e início das pesquisas sobre cana no país}

De início, portanto, o ciclo da cana-de-açúcar estabeleceu-se principalmente na região Nordeste do Brasil. Enfrentou períodos de dificuldade, com a introdução da cana no Caribe e a produção de açúcar de beterraba na França no período de Napoleão Bonaparte, como forma de contornar a falta de açúcar na Europa continental ${ }^{6}$.

5 Veja ao final do livro a lista completa de referências das figuras.

6 Ver $<$ www.toneis.com.br/modules.php?name=News\&file=article\&sid=55>. 
No apogeu do ciclo, nos séculos XVI e XVII, o açúcar era comercializado originalmente na forma de rapadura. Posteriormente, introduziram-se tachos nos banguês dos engenhos de açúcar. O caldo podia então ser concentrado, e a massa cristalizada podia ser colocada, ainda quente, em formas de argila ou madeira, nas quais terminava o processo de cristalização e retirada do melaço. O açúcar, já cristalizado em um torrão de forma cônica, podia então ser retirado da forma e armazenado. A estes torrões de açúcar dava-se o nome de "pães de açúcar". Em decorrência da semelhança de formato com esses pães de açúcar, a montanha símbolo da cidade do Rio de Janeiro foi denominada "Pão de Açúcar"” (Figura 3).
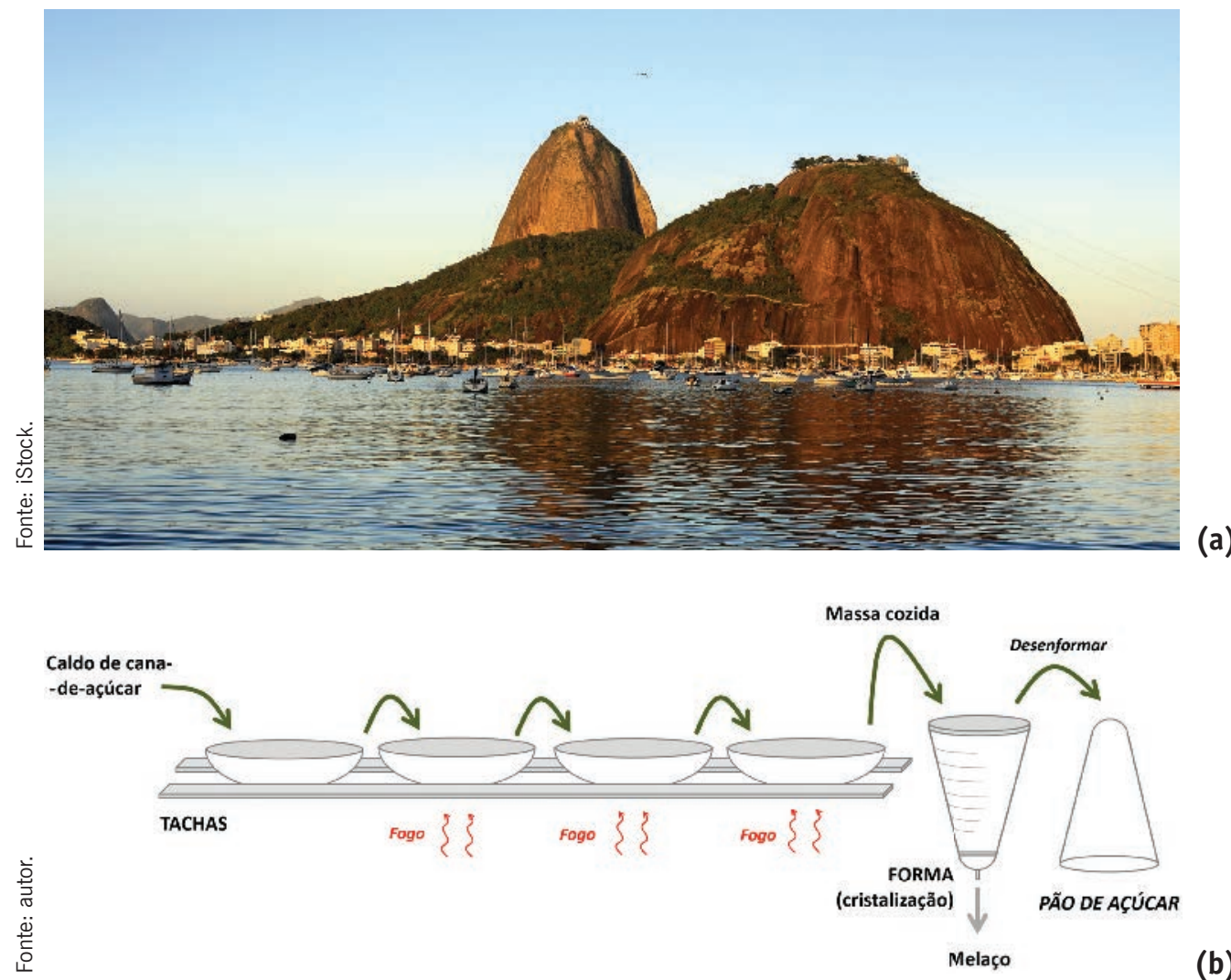

(b)

Figuras 3a e 3b: Pão de Açúcar no Rio de Janeiro, assim denominado pela semelhança com os torrões de açúcar.

$7 \quad$ Ver <www.bondinho.com.br/origem-do-nome/>. 
Do ponto de vista energético, bioenergias de diferentes origens (madeira, carvão vegetal, cana-de-açúcar, ceras, entre outros) foram utilizadas desde o início da colonização, e ainda vêm sendo até os dias de hoje no Brasil.

A biodiversidade brasileira já chamava a atenção do mundo. No início do século XIX, muitos naturalistas europeus, como Alexander von Humboldt, em 1800, Auguste de Saint-Hilaire, em 1816, Carl Friedrich Philipp von Martius, em 1817 e Charles Darwin, em 1833, entre outros, visitaram o país, retratando as abundantes e exóticas espécies vegetais. Em 1808, Dom João VI criou o Jardim Botânico do Rio de Janeiro, origem do atual Instituto de Pesquisas Jardim Botânico do Rio de Janeiro.

Entre 1847 e 1895, Louis Pasteur, na França, desenvolveu estudos sobre os fundamentos da fermentação alcoólica (Amorim, 2005). Em 1887, Dom Pedro II criou o Instituto Agronômico (IAC), inspirado pelo sucesso das pesquisas agronômicas norte-americanas. No mesmo ano, Franz Wilhelm Dafert apresentou uma relação de 42 variedades de canas nobres da coleção, entre as quais se destacavam: Listrada, Cristalina, Kavangire, Rajada, Tiambo, Bois Rouge, Bourbon, Cayana, Imperial, Poudre d'Or e Rosa (Dafert, 1893, 1894 e 1895, apud Figueiredo, 2011 e Dinardo-Miranda, Vasconcelos e Landell, 2008).

Até o fim do século XIX, houve um domínio absoluto da bioenergia tradicional (extrativismo de madeira) na matriz energética brasileira (Guerra e Cortez, 1992). Enquanto isso, principalmente na Europa, várias tecnologias ligadas à fabricação do açúcar e do álcool estavam sendo desenvolvidas, como as máquinas a vapor que precederam o Ciclo Rankine, vindo a possibilitar a "cogeração", o uso do vácuo na evaporação do caldo, reduzindo o consumo de energia, o processo de fermentação alcoólica, além do desenvolvimento da destilação. Já no final do século XIX, desenvolvia-se na França a destilação fracionada do álcool, vindo a permitir seu uso farmacêutico, químico e combustível (Mariller, 1951).

Assim, como a cana-de-açúcar já era considerada uma cultura importante no estado de São Paulo, o Instituto Agronômico, que já havia iniciado suas pesquisas com a cana-de-açúcar em 1892 com Franz W. Dafert, criou seu programa de variedades a partir da década de 1920 (Szmrecsányi, 1979). Mais sobre a história das pesquisas do IAC em cana-de-açúcar é relatado em Figueiredo et al. (2011). 


\section{Início do século XX: mudança na matriz energética mundial com a introdução da eletricidade e dos combustíveis líquidos}

Já no início do século XX observou-se a introdução da eletricidade no Brasil, tendo a geração iniciado com o aproveitamento do potencial hídrico. Também nas primeiras décadas do século XX, pode-se notar a introdução das fontes fósseis (carvão mineral e petróleo), dando maior complexidade à nascente matriz energética brasileira.

Acontecia nessa época um processo de modernização da indústria açucareira (Szmrecsányi, 1979) cujo objetivo era aumentar o rendimento da cana-de-açúcar e transformar os velhos engenhos em modernas usinas, possibilitando o processamento centralizado da cana de uma região. Assim nasceram os "engenhos centrais".

Em 1903, o então presidente Rodrigues Alves inaugurou a Exposição Internacional de Aparelhos a Álcool e teve lugar, também no Rio de Janeiro, o Primeiro Congresso Nacional de Aplicação Industrial do Álcool. Segundo relato de Henry Joseph Júnior (2009) baseado no livro de Silva e Frachetti (2008), a mídia da época afirmava: "O querosene, importado do estrangeiro a bom dinheiro e que não tem as mesmas vantagens de higiene, duração e economia que a do álcool produzido em nossos engenhos, precisa ser, por este imediatamente substituído". O assunto também é tratado por Roberta Barros Meira (2012) em sua tese O emprego do álcool como agente de luz, força motriz e calor: uma solução para a crise açucareira da Primeira República.

Data de 1908 a criação do Ford modelo T por Henry Ford, nos EUA, que utilizava álcool e também gasolina como combustíveis (Figura 4).

Ainda segundo Meira (2012), o crescimento da frota de veículos no Brasil foi bastante rápido, alcançando $220 \mathrm{mil}$ unidades em 1929 e aumentando significativamente o consumo de gasolina importada. Portanto, a substituição de parte da gasolina importada por álcool apresentava importância energética e econômica.

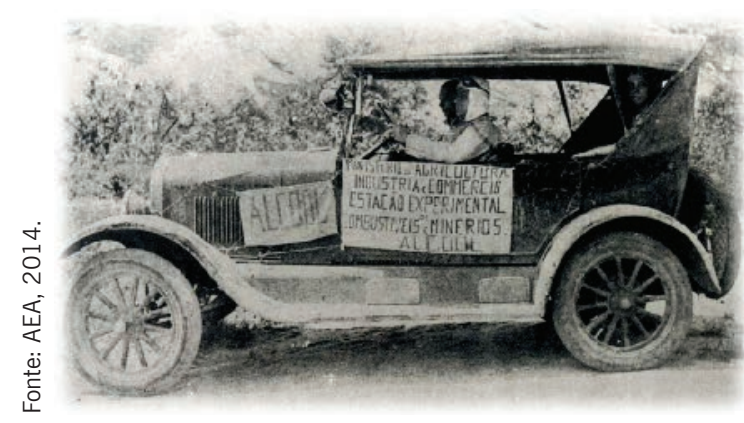

Figura 4: Ford modelo T, primeiro flex. 
Um pouco antes, em 1908, Arthur Harden e William John Young elaboram a equação da fermentação alcoólica (Amorim, 2005):

$$
\mathrm{C}_{6} \mathrm{H}_{12} \mathrm{O}_{6} \rightarrow 2 \mathrm{C}_{2} \mathrm{H}_{5} \mathrm{OH}+2 \mathrm{CO}_{2}
$$

Na década de 1920 observou-se o surgimento de empresas do setor açucareiro, como a Dedini, que viriam a desempenhar papel fundamental no processo de industrialização do país, notadamente no interior do estado de São Paulo, se tornando verdadeiros ícones do setor sucroalcoleiro no Brasil.

Em 23 de junho de 1927, a Usina Serra Grande Alagoas (USGA) lançou o álcool-motor, no Recife, o combustível a base de álcool alternativo à gasolina. Foi o primeiro grande empreendimento brasileiro em álcool combustível.

\section{Década de 1930: os primeiros passos na conversão energética da biomassa e o início da produção de álcool no Brasil}

A adição obrigatória de álcool à gasolina importada veio em 1931 (Brasil, 1931). Foi criada em 1932 a Estação Experimental de Combustíveis e Minérios, posteriormente transformada, em 1933, no Instituto Nacional de Tecnologia (Figura 5), onde Eduardo Sabino de Oliveira e Lauro de Barros Siciliano deram continuidade aos estudos do uso automotivo de álcool, iniciados na Escola Politécnica de São Paulo (Oliveira, 1937; INT, 1979).

A criação do Instituto do Açúcar e do Álcool (IAA) por Getúlio Vargas e o início do uso de álcool na gasolina

O presidente Getúlio Vargas (Figura 6) criou em 1933 o Instituto do Açúcar e do Álcool (IAA) motivado por uma crise no setor açucareiro ${ }^{8}$, já que o uso de álcool de cana poderia ajudar os produtores de açúcar a arbitrar entre a produção de açúcar e de etanol, ao mesmo tempo que atenuaria o consumo de gasolina importada no país ${ }^{9}$. Nesse sentido, pode-se creditar a Vargas o nascimento da ideia de um Estado empreendedor usando a bioenergia da cana-de-açúcar como vetor de desenvolvimento.

8 A década de 1930 viria a ser de prosperidade para o setor açucareiro, com o aumento do consumo de açúcar na Europa.

9 O Decreto-Lei de 1931 determinava uma mistura de 5\% de álcool à gasolina importada, segundo Henry Joseph Júnior, em Silva e Fischetti (2008). 
No entanto, as décadas de 1920, 1930 e 1940 foram marcadas pela discussão sobre a existência e a exploração de petróleo no Brasil. Vale a lembrança do empenho de Monteiro Lobato na questão do petróleo (O escândalo do petróleo e ferro, 1936). O movimento "O petróleo é nosso!", encabeçado por intelectuais da época, levaria à criação da Petrobras na década de 1950.

Em 1931, com o Decreto-Lei n. 19.717, passa a ser obrigatório adicionar álcool de cana a toda gasolina no Brasil. O teor de álcool, embora limitado a 5\%, variou ao longo do tempo até a década de 1970 na faixa de zero a 5\%, em função da disponibilidade do álcool. Durante a Segunda Guerra Mundial, com a gasolina importada em falta, há relatos de uso de teores de álcool superiores a 50\%. Em 22 de setembro de 1942, por meio do lançamento do Decreto-Lei n. 4.722, o governo declara a indústria alcooleira de interesse nacional e estabelece preços mínimos para o produto $^{10}$.

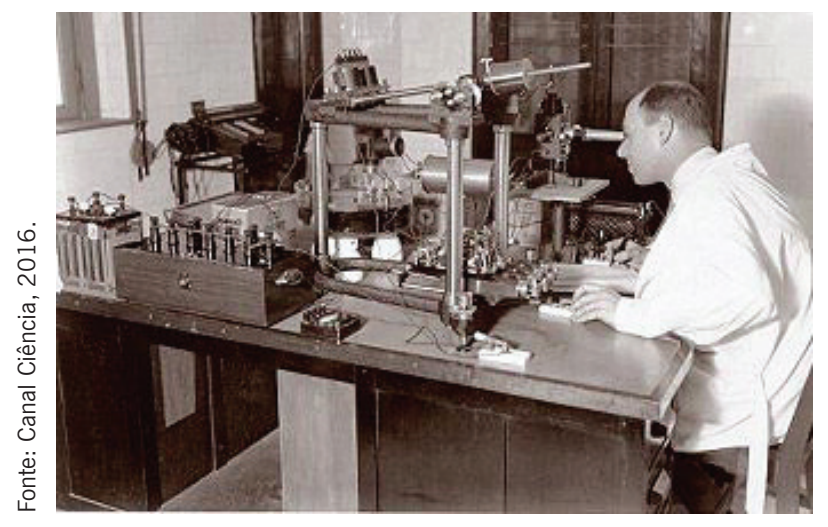

Figura 5: Laboratório do Instituto Nacional de Tecnologia (INT).

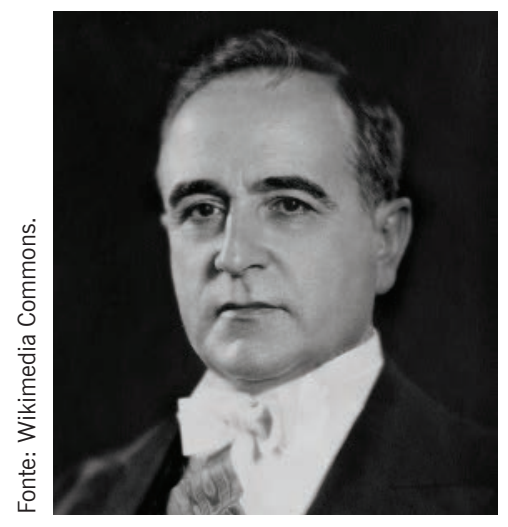

Figura 6: Getúlio Vargas.

No entanto, mesmo antes do fim da Segunda Guerra Mundial, o petróleo passou a dominar os transportes e a hidroeletricidade assumiu importância crescente. Apesar disso, a bioenergia, tanto tradicional (lenha e carvão vegetal) como moderna (etanol e bagaço de cana), mantinha sua importância. A lenha perdia peso na matriz, enquanto o uso da cana para fins energéticos tornava-se cada vez maior, sobretudo a partir de 1975. No período 1930 a 1975, o uso médio ${ }^{11}$ de etanol na gasolina foi de 5\% a 7\% (Nogueira, 2008; Figura 7).

10 Conforme: <www.novacana.com/etanol/historia-legislacao/>.

11 Valores médios anuais, calculados a partir dos valores mensais definidos pela legislação (assume consumos mensais constantes). 
Em 1934, Oswaldo Gonçalves de Lima (Figura 8) e Anibal Ramos de Matos, da Universidade Federal de Pernambuco, demonstraram que a vinhaça poderia ser utilizada como fertilizante no solo. Apesar do baixo pH $(5,0$ a 6,0) o solo tratado com ele poderia ser alcalinizado, apresentando um pH próximo de 7,0. Oswaldo Lima criou em 1958, no Recife, o Instituto dos Antibióticos, hoje Departamento de Antibióticos da UFPE (Amorim, 2005).

É de 1938 o livro Technologia da Fabricação do Álcool, de Luiz Machado Baeta Neves, superintendente técnico das Usinas Junqueira (Amorim, 2005).

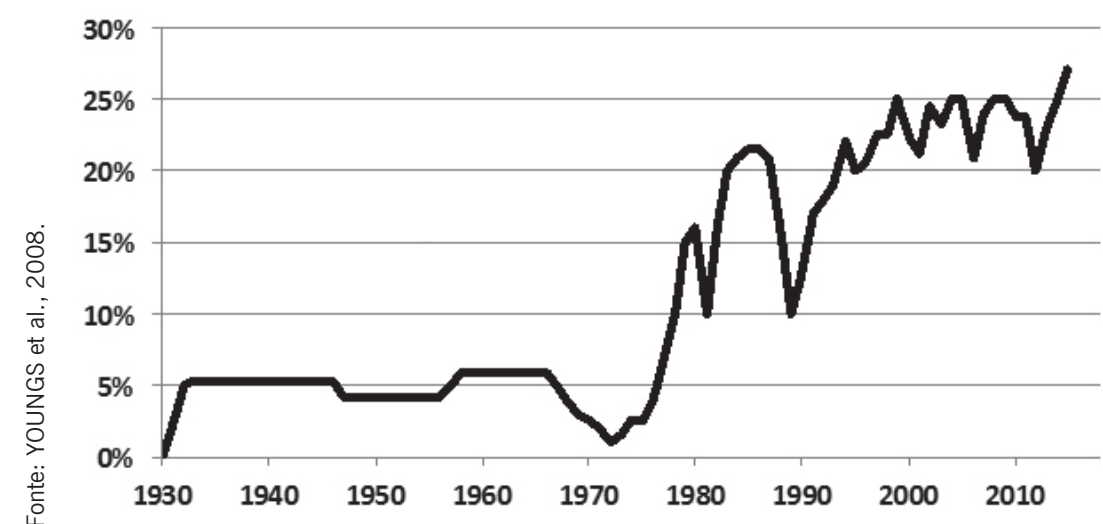

Figura 7: Teor de etanol na gasolina brasileira entre 1930 e 2010.

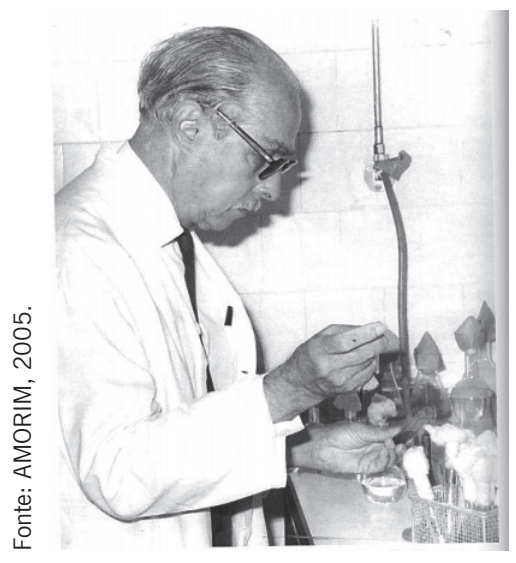

Figura 8: 0swaldo Gonçalves de Lima.

\section{Década de 1940: o mundo está em guerra, e o Brasil sente}

A Segunda Guerra Mundial trouxe problemas para o abastecimento de gasolina do país. Como toda a gasolina era importada, outros combustíveis vieram a ser valorizados além do álcool, como o carvão vegetal. Carros, ônibus e caminhões a gasogênio eram vistos circulando nas ruas das grandes cidades brasileiras. Estima-se que o uso médio de álcool na gasolina no período 1942 a 1946 tenha atingido 42\% (Leal, 2008).

Antes do fim da década de 1940, chegou ao Brasil o processo Melle-Boinot, divulgado pela empresa Les Usines de Melle, tradicional fornecedora de equipamentos (Amorim, 2005). 


\section{Década de 1950: criação do Instituto Zimotécnico, da ESALQ ${ }^{12} /$ USP}

Em 1950, Jayme Rocha de Almeida criou o Instituto Zimotécnico, na ESALQ/USP, e, anos depois, em 1956, montou a Destilaria Piloto ${ }^{13}$ no Departamento de Agroindústria, Alimentos e Nutrição (LAN) da ESALQ/USP. O Instituto Zimotécnico se dedica às leveduras e à fermentação alcoólica.

Entre as pesquisas realizadas pelo Instituto Zimotécnico, destacam-se os trabalhos pioneiros sobre vinhaça e seu uso como fertilizante ${ }^{14}$, de Guido Ranzani e Jorge Leme Júnior ${ }^{15}$. Atualmente, há um grupo de pesquisas bem estabelecido estudando cachaça de qualidade no IZ da ESALQ com pesquisadores como André Alcarde e Aline Bortoletto.

Um outro grupo que estudou o tema da aguardente de cana (cachaça) foi o de João Batista de Almeida, da Escola de Engenharia de Lorena (EEL/USP), com o desenvolvimento da "destilação lenta" para alambiques e destilarias de maior porte. Há também outros grupos de pesquisa em aguardente e cachaça na Universidade Federal de Lavras (UFLA) e na Universidade Federal de Viçosa (UFV).

\section{3: a criação da Petrobras}

A criação da Petrobras se deu em 3 de outubro de 1953 por Getúlio Vargas, por meio da Lei n. 2.004 de 1952. A nova empresa ficou responsável pela execução do monopólio estatal do petróleo para exploração, refino do produto nacional e estrangeiro, transporte marítimo e sistema de dutos, tendo como objetivo tornar o país autossuficiente em petróleo.

Com a criação da Petrobras e a introdução da indústria automobilística na década de 1950, pensava-se que o país rapidamente alcançaria a autossuficiência em petróleo e que, mais do que isso, poderia criar um modelo de desenvolvimento econômico baseado na produção de veículos, leves e pesados, usando o petróleo como energia.

12 Escola Superior de Agricultura Luiz de Queiroz da Universidade de São Paulo.

13 Conforme <www5.usp.br/22638/novas-tecnologias-desenvolvidas-na-esalq-aprimoram-qualidade-de-aguardente/>.

14 Conforme <www.scielo.br/scielo.php?pid=S0071-12761954000100012\&script=sci_arttext .

15 Jorge Leme Júnior ajudou na criação do curso de Engenharia Açucareira da Unicamp, que, infelizmente, não prosperou. 
Segundo Getúlio Vargas:

A organização da Petrobras foi concebida dentro de um ponto de vista nitidamente nacionalista; ela dará o petróleo do Brasil aos brasileiros e tornará possíveis os recursos financeiros vultosos de que necessitamos para explorar uma das maiores fontes de riquezas da civilização. Essa bandeira nacionalista, eu a venho desfraldando em toda a minha vida e ninguém logrará arrebatá-la de minhas mãos. Coube ao meu passado Governo elaborar a legislação de minas que nacionalizou a propriedade e a exploração de riquezas do nosso subsolo, cristalizando-se, pela primeira vez, a defesa do patrimônio mineral do Brasil ${ }^{16}$.

\section{Década de 1960: sociedade de Técnicos Açucareiros Alcooleiros do Brasil (STAB) e do Centro de Tecnologia COPERSUCAR (CTC)}

\section{3: criação da Sociedade de Técnicos Açucareiros Alcooleiros do Brasil (STAB)}

Um grupo de técnicos do setor sucroalcooleiro e professores da ESALQ/USP fundaram, em 1963, a Sociedade de Técnicos Açucareiros Alcooleiros do Brasil (STAB) ${ }^{17}$ com o objetivo básico, já naquela época, de propiciar o intercâmbio científico e cultural entre as várias regiões produtoras de cana-de-açúcar, álcool e derivados, não só no Brasil como também no exterior, sempre primando pela conquista e aprimoramento de novas técnicas e procedimentos colocados em prática desde o campo até a indústria.

\section{9: criação do Centro de Tecnologia Copersucar (CTC)}

"O Centro de Tecnologia Copersucar (CTC) foi criado em 1969, em uma iniciativa de um grupo de usinas da região de Piracicaba, a 160 quilômetros da capital paulista, com o objetivo de investir no desenvolvimento de variedades mais produtivas e agregar qualidade à produção de açúcar e álcool. Em 2004, entrou em uma nova era: foi reestruturado como uma OSCIP ${ }^{18}$, tendo $60 \%$ do setor canavieiro como associado, com o objetivo de se tornar o principal centro mundial de desenvolvimento e integração

16 Pronunciamento de Getúlio Vargas quando da criação da Petrobras. Disponível em: <www.memoria.petrobras.com.br>.

17 Ver $<$ www.stab.org.br/ $>$.

18 Ver <www.sebrae.com.br/sites/PortalSebrae/bis/OSCIP-\%E2\%80\%93-organiza\%C3\%A7\%C3\%A3o-da-sociedade-civil-de-interesse-p\%C3\%Bablico . 
de tecnologias disruptivas da indústria sucroenergética. Em 2011, transformou-se em uma empresa de tecnologia com fins lucrativos, e seus acionistas investiram para que o CTC seja capaz de vencer o desafio de dobrar, de maneira economicamente sustentável, a taxa de inovação do setor.

Em seus 46 anos de vida, o CTC deixou sua marca no desenvolvimento da cultura da cana-de-açúcar no Brasil. Nesse período, o ganho de eficiência foi inegável: a produtividade da cana-de-açúcar quase dobrou em relação aos anos 1960, o teor de açúcar na cana aumentou em 50\% e a produtividade agroindustrial saltou de 2,6 mil litros para mais de 7 mil litros de etanol por hectare, enquanto o custo de produção caiu de cerca de 3 reais para menos de 1 real por litro" ${ }^{19}$.

Novas variedades de cana-de-açúcar desenvolvidas pelos especialistas do CTC possibilitaram a expansão dos canaviais brasileiros por novos 3 milhões de hectares. Tendo recebido, em toda a sua história, investimentos inferiores a 4 bilhões de reais, calcula-se que a sua contribuição para a economia brasileira seja de 1 trilhão de reais.

Mais importante centro de pesquisas em cana-de-açúcar do mundo, o CTC manteve o mesmo caráter inovador e a busca pela excelência em seus resultados que agora norteiam uma empresa moderna e independente, cujos acionistas respondem por cerca de $60 \%$ da cana-de-açúcar moída na região Centro-Sul do Brasil.

Seu primeiro diretor, Manoel Sobral Júnior, vindo da Unicamp, montou uma grande equipe para fazer face aos desafios tecnológicos. Entre eles se destacam: Carlos Vaz Rossell, Jaime Finguerut, Isaías Macedo, Manoel Regis Lima Verde Leal e William Burnquist; pela tecnologia industrial aplicada às usinas, Pierre Chenu, Deon J. L. Hullet, Sidney Brunelli e, posteriormente, Mario Myaiese e Suleiman José Hassuani.

Um aspecto importante, e nem sempre lembrado atualmente, é que o CTC promoveu uma importante mudança de referência tecnológica do setor industrial: os processos e equipamentos disponíveis eram de influência cubana ou europeia (França, Inglaterra, Holanda) e as tecnologias de melhor desempenho à época eram a sul-africana e a australiana. O CTC trouxe a referência sul-africana ao Brasil, cujas soluções eram mais adequadas às características brasileiras. Essa mudança de referência se estendeu aos fabricantes

19 Ver <www.ctcanavieira.com.br/nossahistoria.html>. 
de equipamentos, que, rapidamente, absorveram e passaram a desenvolver tecnologia própria nacional, e de melhor desempenho inclusive do que a sul-africana, para o processamento de cana. $O$ processo etanol se desenvolveu com intensidade principalmente com recursos nacionais, a partir da base existente, e o processo açúcar brasileiro não evoluiu, pois não existiram investimentos em açúcar por não haver pressão de demanda por aumento de capacidade. A tecnologia de açúcar permaneceu defasada e inferior ao estado da arte internacional até meados da década de 1990, quando ocorreu a necessidade de aumento de capacidade, conforme veremos mais adiante.

\section{Década de 1970: Plano Nacional de Melhoramento da Cana-de-Açúcar (Planalsucar) e primeiro choque do petróleo}

\section{1: criação do Planalsucar}

Em 1971, foi criado o Plano Nacional de Melhoramento da Cana-de-açúcar (Planalsucar) ${ }^{20}$, órgão ligado ao IAA e voltado ao desenvolvimento de novas variedades, cujo objetivo era contribuir com o aumento da produtividade da atividade canavieira no país. As atividades do Planalsucar também incluíam a previsão de safras. Segundo Luiz Carlos Corrêa Carvalho, o "Caio", ex-superintendente do Planalsucar e hoje diretor da Associação Brasileira do Agronegócio (ABAG), o Planalsucar desempenhou um papel muito importante no Proálcool, dado que muitos estudos para o avanço da cana já tinham sido realizados pelo órgão ${ }^{21}$. Segundo Octávio Antonio Valsechi, pesquisador da UFSCar, “o Planalsucar foi antecedente do Proálcool com o objetivo de desenvolver em três anos regiões para plantio de cana e adaptar variedades para estas novas regiões. O berço do Proálcool é onde hoje está o CCA/UFSCar. Foi ali que tudo começou!".

20 Conforme <www.canaonline.com.br/conteudo/ridesa-comemora25-anos-de-historia-em2015.html\#.VehT0HIRGUk>.

21 Conforme <http://economia.estadao.com.br/noticias/geral,planalsucar-estimulou-etanol-no-pais-imp-,642599>. 


\section{3: primeiro choque do petróleo}

No primeiro choque do petróleo, em 1973, cuja causa principal foi o embargo dos países membros da recém-criada Organização dos Países Exportadores de Petróleo (OPEP), os preços do petróleo passaram de 1,9 dólar/barril em 1972 a 11,2 dólares/barril em 1974. Dado que o Brasil importava quase $80 \%$ do petróleo que consumia - o que representava cerca de $50 \%$ do valor total de suas importações -, o impacto desse aumento foi muito significativo para a economia brasileira. Algo precisava ser feito, e rapidamente, para aliviar a dependência do petróleo importado.

Por outro lado, o setor açucareiro vivia momentos difíceis, com preços declinantes do açúcar no mercado internacional, o que também fez despertar o interesse dos empresários pela produção do álcool combustível.

Mais detalhes sobre a história da indústria canavieira de 1930 a 1975 podem ser encontrados em O planejamento da agroindústria canavieira do Brasil, 1930-1975, de Tamás Szmrecsányi (1979, Figura 9). Pedro Ramos, da Unicamp, também apresenta informações valiosas sobre a história da indústria da cana no Brasil, com trabalhos sobre o desenvolvimento da agroindústria canavieira no Brasil (Ramos et al., 1995; Ramos, 1999 e Ramos, 2010).

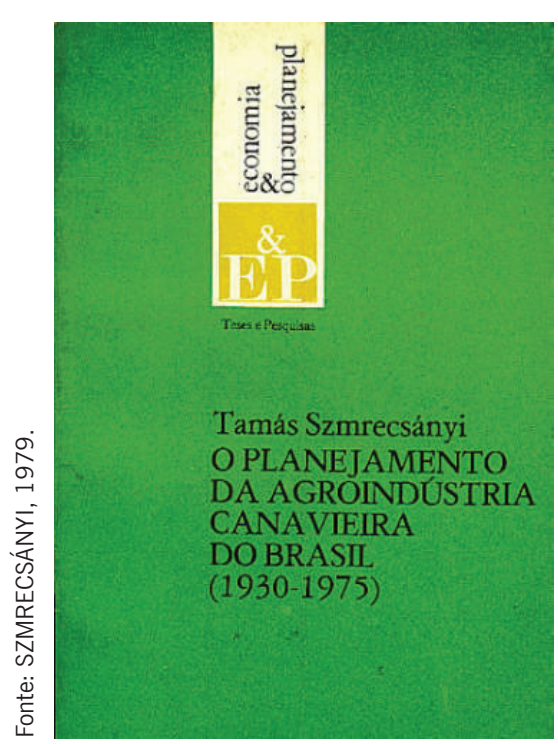

Figura 9: Capa do livro de Tamás Szmrecsányi sobre a história da indústria da cana. 